\title{
Genome sequencing identified novel mechanisms underlying virescent mutation in upland cotton Gossypiuma hirsutum
}

Jin Gao, Yang Shi, Wei Wang, Yong-Hui Wang, Hua Yang, Qing-Hua Shi, Jian-Ping Chen, Yan-Ru Sun and Li-Wang Cai

\begin{abstract}
Background: Virescent mutation broadly exists in plants and is an ideal experimental material to investigate regulatory mechanisms underlying chlorophyll synthesis, photosynthesis and plant growth. Up to date, the molecular mechanisms in two virescent mutations have been clarified in cottons (Gossypiuma hirsutum). A virescent mutation has been found in the cotton strain Sumian 22, and the underlying molecular mechanisms have been studied.

Methods: The virescent mutant and wild type (WT) of Sumian 22 were cross-bred, and the $F_{1}$ population were selfpollinated to calculate the segregation ratio. Green and yellow leaves from $F_{2}$ populations were subjected to genome sequencing and bulked-segregant analysis was performed to screen mutations. Real-time quantitative PCR (RT-qPCR) were performed to identify genes in relations to chlorophyll synthesis. Intermediate products for chlorophyll synthesis were determined to validate the RT-qPCR results.

Results: The segregation ratio of green and virescent plants in F2 population complied with 3:1. Compared with WT, a $0.34 \mathrm{Mb}$ highly mutated interval was identified on the chromosome D10 in mutant, which contained 31 genes. Among them, only ABCl1 displayed significantly lower levels in mutant than in WT. Meanwhile, the contents of Mg-protoporphyrin IX, protochlorophyllide, chlorophyll a and b were all significantly lower in mutant than in WT, which were consistent with the inhibited levels of $A B C / 1$. In addition, a mutation from $A$ to $T$ at the -317 bp position from the start codon of $A B C / 1$ was observed in the genome sequence of mutant.

Conclusions: Inhibited transcription of $A B C / 1$ might be the mechanism causing virescent mutation in Sumian 22 cotton, which reduced the transportation of protoporphyrin IX to plastid, and then inhibited Mg-protoporphyrin IX, Protochlorophyllide and finally chlorophyll synthesis. These results provided novel insights into the molecular mechanisms underlying virescent mutation in cotton.
\end{abstract}

Keywords: Virescent mutant, Sumian 22, ABCI1, Rapid mapping, Genome, Chlorophyll synthesis

\footnotetext{
*Correspondence: jsclw86@163.com

Jiangsu Coastal Area Institute of Agricultural Sciences/Observation and Experimental Station of Saline Land of Costal Area, Ministry of Agriculture, Yancheng 224002, Jiangsu, People's Republic of China
}

(c) The Author(s). 2021 Open Access This article is licensed under a Creative Commons Attribution 4.0 International License, which permits use, sharing, adaptation, distribution and reproduction in any medium or format, as long as you give appropriate credit to the original author(s) and the source, provide a link to the Creative Commons licence, and indicate if changes were made. The images or other third party material in this article are included in the article's Creative Commons licence, unless indicated otherwise in a credit line to the material. If material is not included in the article's Creative Commons licence and your intended use is not permitted by statutory regulation or exceeds the permitted use, you will need to obtain permission directly from the copyright holder. To view a copy of this licence, visit http://creativecommons.org/licenses/by/4.0/ The Creative Commons Public Domain Dedication waiver (http://creativecommons.org/publicdomain/zero/1.0/) applies to the data made available in this article, unless otherwise stated in a credit line to the data. 


\section{Background}

As one of the important economic crops in the world, cotton is of great significance to provide materials for the global textile industry. Scientists are always trying to breed high-quality cotton breeds. Investigation of the molecular mechanisms underlying plant growth and production of cotton may facilitate the molecular breeding process.

Virescent mutation is characterized by yellowish leaves at the early stage, which gradually become normal green leaves at maturity [1]. The virescent mutation is an easily identifiable character and has been observed in various plant species including rape [2], Arabidopsis [3], rice [4], cucumber [5], maize [6] and cotton [7]. The virescent mutants in leaves directly or indirectly affect the biosynthesis pathway of chlorophyll, resulting in the imbalance of the content and proportion of photosynthetic pigments, finally changing the leaf color [8-10]. In general, the virescent mutation is genetically stable and the genetic mode of virescent mutant is simple, controlled by 1-2 pairs of recessive genes. Thus, virescent mutant plants together with wild type (WT) plants provide ideal experimental materials for investigations of mechanisms regulating the expression of genes in relation to chlorophyll synthesis, which are important to photosynthesis and plant growth.

In allotetraploid cotton strains, 22 virescent mutants have been identified, which were suspected to the mutations of 24 genes. However, to the best of our knowledge, only two molecular mechanisms have been clarified. First, in the virescent mutant of the cotton strain T582, the normal functioning of Mg-chelatase I subunit (CHLI) was disturbed [11]. Next, this mutant was localized to a $20 \mathrm{~kb}$ interval on the chromosome 20 and the responsible gene was named GhRVL, which was homologous to CHLI in Arabidopsis [12]. Similar results were also found in the virescent phenotype of the cotton strain ZM050400 [1]. Compared with the cotton reference genome of the TM-1 stain [13], GhRVL was localized to the interval between 0.7 and $3.9 \mathrm{Mb}$ on chromosome D10 in the TM-1 genome. Second, another virescent gene was identified on the chromosome D04 and the candidate gene was named GhPUR4, which affected the normal function of formylglycinamide ribotide amidotransferase (FGAMS) in the fourth step of the de novo purine biosynthesis pathway and finally resulted in the reduction of chlorophyll content, abnormal chloroplast development and virescent true leaves [14]. These results revealed the molecular mechanisms underlying virescent leaves in certain cotton strains. However, other virescent strains may not all follow these mechanisms. More studies are still required to further investigate the molecular mechanisms underlying virescent mutations in cotton.
Sumian 22 (Gossypiuma hirsutum) is an important upland cotton variety in China. It shows high yield, good quality of fiber, and high resistance to diseases [15]. In 2004, a natural virescent mutant was found in the Sumian 22 populations, whose leaves were yellow at the young stage but then turned to light green at the boll stage [16]. Clarifying the genetic basis of leaf color mutation has important theoretical and practical value in cotton research [17]. Considering the insufficient understanding of molecular mechanisms underlying virescent mutation in cotton, it is still necessary to also study the mechanisms underlying the virescent Sumian 22 strain.

Bulked-segregant analysis (BSA) is a very useful approach to identify genetic locus for simple quality trait, which separately pools the DNA of extreme individuals with contrasting phenotypes from a segregating population followed by screening of mutated molecular markers between parents and bulks [18, 19]. Based on next-generation sequencing (NGS), BSA analysis greatly accelerates the period of gene mapping research [20]. This method has been successfully applied to identify genes regulating genic male sterility in sesame [21], virescent mutation in rapeseed [22], plant height in maize [23] and rate of leaf initiation in barley [24].

In the present study, the virescent mutant (mutant) and wild green type (WT) of Sumian 22 were cross-bred and the $F_{2}$ population was separated to green and yellow pools. BSA was conducted to search single nucleotide polymorphisms (SNP) between the two pools. Based on the SNP results, candidate genes were predicted, their mRNA levels were examined using real-time quantitative PCR (RT-qPCR) and the changes of potential intermediate metabolites for chlorophyll synthesis were also determined. Overall, these results aimed to explain the molecular mechanisms underlying the virescent trait in Sumian 22 cotton, which provides a basis to further understand the molecular mechanisms underlying the virescent phenomenon and regulation of chlorophyll synthesis in cotton.

\section{Results}

The virescent mutation is a recessive gene in Sumian 22

The young leaves of mutant were clearly distinguished by a yellowish leaf color (Fig. 1A), significantly different from the WT (Fig. 1C). At the mature stage, mutant leaves became green (Fig. 1B), but still slightly different from the WT (Fig. 1D).

In the cross-breed between mutant and $\mathrm{WT}$, all $\mathrm{F}_{1}$ plants revealed green leaves. However, in the selfpollinated $\mathrm{F}_{2}$ population, $72.8 \%$ and $27.2 \%$ individuals revealed green and yellow leaves, respectively. The ratio between green- and yellow-leaved plants was not significantly different from 3:1 (Table 1), suggesting the virescent mutation in Sumian 22 is a recessive mutation. 

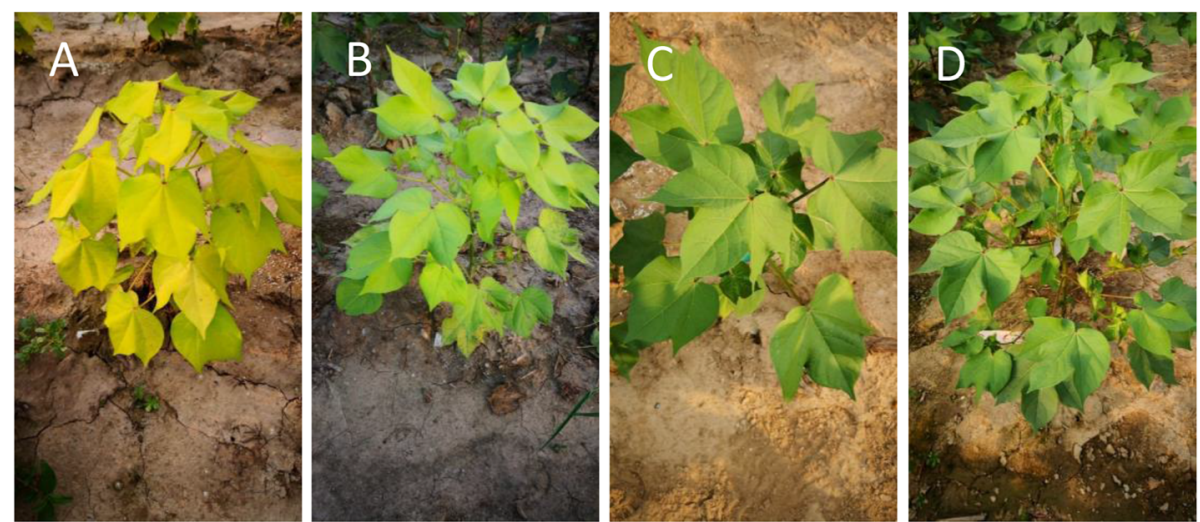

Fig. 1 Phenotypes of leaves in the virescent mutant (Mutant) of Sumian 22 and wild type (WT) of Sumian 22. A Mutant at the young stage; B WT at the young stage; $\mathbf{C}$ mutant at maturity; $\mathbf{D}$ WT at maturity

\section{Rapid delimitation of a candidate genomic region by BSA-seq}

Genome sequencing obtained 124.46 and 127.67 million reads for WT and mutant, with the genome coverage of $94.66 \%$ and $94.63 \%$, respectively. Considering the heterogeneity of plants in $F_{2}$ population, the G- and Y-pools were sequenced, which produced 822.93 and $680.68 \mathrm{M}$ reads, covering $95.30 \%$ and $95.30 \%$ of the whole genome, respectively (Additional file 1: Table $\mathrm{S} 1$ ).

Between WT and mutant, 958,198 SNPs and 528,693 small InDels polymorphic markers were identified. The SNP-index plots were similar between G-pool and Ypool at most regions of the genome. However, $\triangle \mathrm{SNP}$ index revealed a higher SNP load at the region from 3.08 to $3.42 \mathrm{Mb}$ on the chromosome D10 according to the reference genome of TM-1 cotton [13] (Fig. 2), which was considered as the unique candidate region of the virescent gene. In this region, 31 coding genes and 597 SNPs were identified.

\section{Determination of gene transcription levels by RT-qPCR}

Seven genes in relation to chlorophyll synthesis were selected to for RT-qPCR. The results showed no significant differences between mutant and WT (Fig. 3), suggesting that the reported mechanism of GhRVL mutation (identical to CHLI in the present study) $[11,12]$ in virescent T582 cotton was not responsible for the virescent mutation in Sumian 22.

To compare the levels of the 31 genes in the candidate region, RT-qPCR assays were performed for both mutant and WT. Among them, 4 genes (Protein SRG1 (SRG1), Floral homeotic protein AGAMOUS (AG), Integrinlinked protein kinase 1 (ILK1), and a function unknown gene) revealed significantly higher, but 3 genes (ER lumen protein-retaining receptor A (ERD2A), Protein gravitropic in the light 1 (GIL1), and ABC transporter I family member 1 (ABCI1)) displayed significantly lower levels in mutant than in WT (Fig. 4). As reported, these genes were mainly functionally related to plant immunity $[25,26]$, carpels development [27], and signal transducer activity [28]. Only ABCI1 (Ghir_D10G003980) was reported to participate in the chlorophyll biosynthesis process [29], thus was considered as the candidate gene for virescent mutation. As reported, ABCI1 was suspected to involve in the Proto-IX transport and distribution in Arabidopsis, which is an essential step of chlorophyll biosynthesis [30].

\section{Contents of chlorophyll precursors and chlorophylls}

To validate the metabolic changes of ABCI1 mutation, intermediate products in the biosynthesis process from protoporphyrin IX (Porto-IX) to chlorophyll were determined. The results showed that contents of Mg-protoporphyrin IX

Table 1 Segregation of leaf color in the $F_{2}$ population of the cross-breed between the wild type and the virescent mutant of Sumian 22 cotton

\begin{tabular}{ll}
\hline Cross & Wild type S22 $\times$ Virescent mutant S22 \\
\hline Number of green leaves plants & 704 \\
Number of yellow leaves plants & 263 \\
Total number of plants & 967 \\
Expected ratio & $3: 1$ \\
$X^{2}$ & 2.49 \\
\hline
\end{tabular}

$X_{0.05}^{2}=3.84, X^{2}<X_{0.05}^{2}$ indicates no significant difference between the observed and expected ratios 


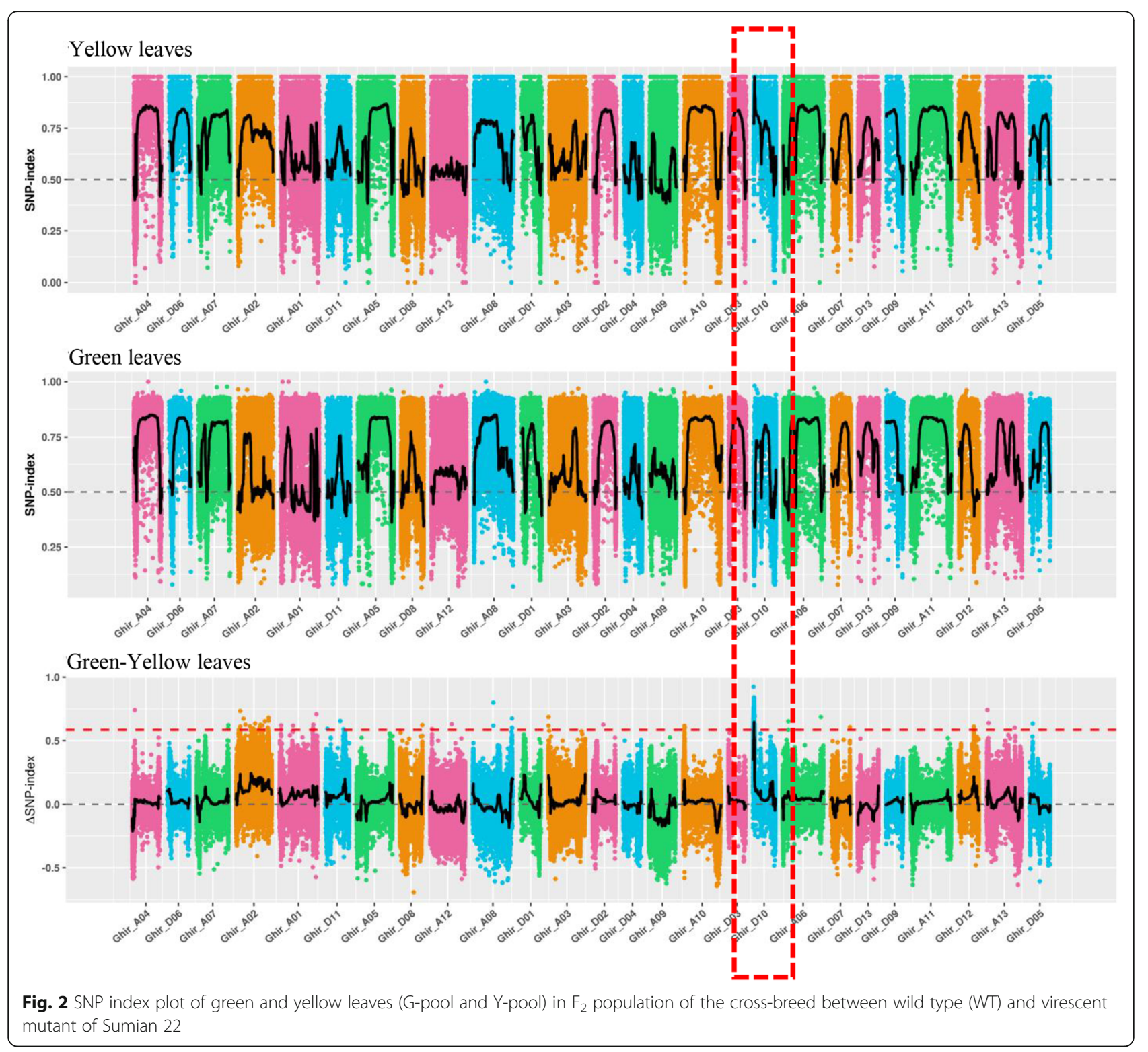

(Mg-Proto IX) and protochlorophyllide (Pchld) were both significantly lower in mutant than in WT (Fig. 5A). Meanwhile, contents of both chlorophyll a and b showed significantly lower values in mutant than in WT (Fig. 5B).

\section{Characterization of mutations potentially affecting $\mathrm{ABCl1}$ transcription in Sumian 22}

The open reading frame (ORF) of ABCI1 in Sumian 22 was $690 \mathrm{bp}$ in length, encoding 229 amino acids. Based on the genome sequencing results, nine SNPs which might potentially affect the transcription of ABCI1 were identified (Additional file 1: Table S2). Among them, one was localized to the exonic region of ABCI1, which is heterozygous in the Y-pool. One was localized to the $5^{\prime}$-untranslated region (5'-UTR). It is heterozygous in the G-pool, but homozygous in the Y-pool. This mutation was in an AT-rich region (Additional file 1: Figure S1). Other seven SNPs were all upstream to both Ghir_D10G003980 and Ghir_D10G003990.

\section{Discussion}

In cotton strains, two virescent mutations have been clarified, which were attributed to the dysfunction of GhRVL and GhPUR4 [1, 12, 14]. However, in the present study, qPCR analyses did observe significant differences in these two genes between mutant and WT, indicating that these two genes were not the mechanisms underlying virescent mutation in Sumian 22 cotton. Thus, WT and virescent mutant of Sumian 22 cotton provide good materials to elucidate novel mechanisms underlying virescent mutation in cotton. 


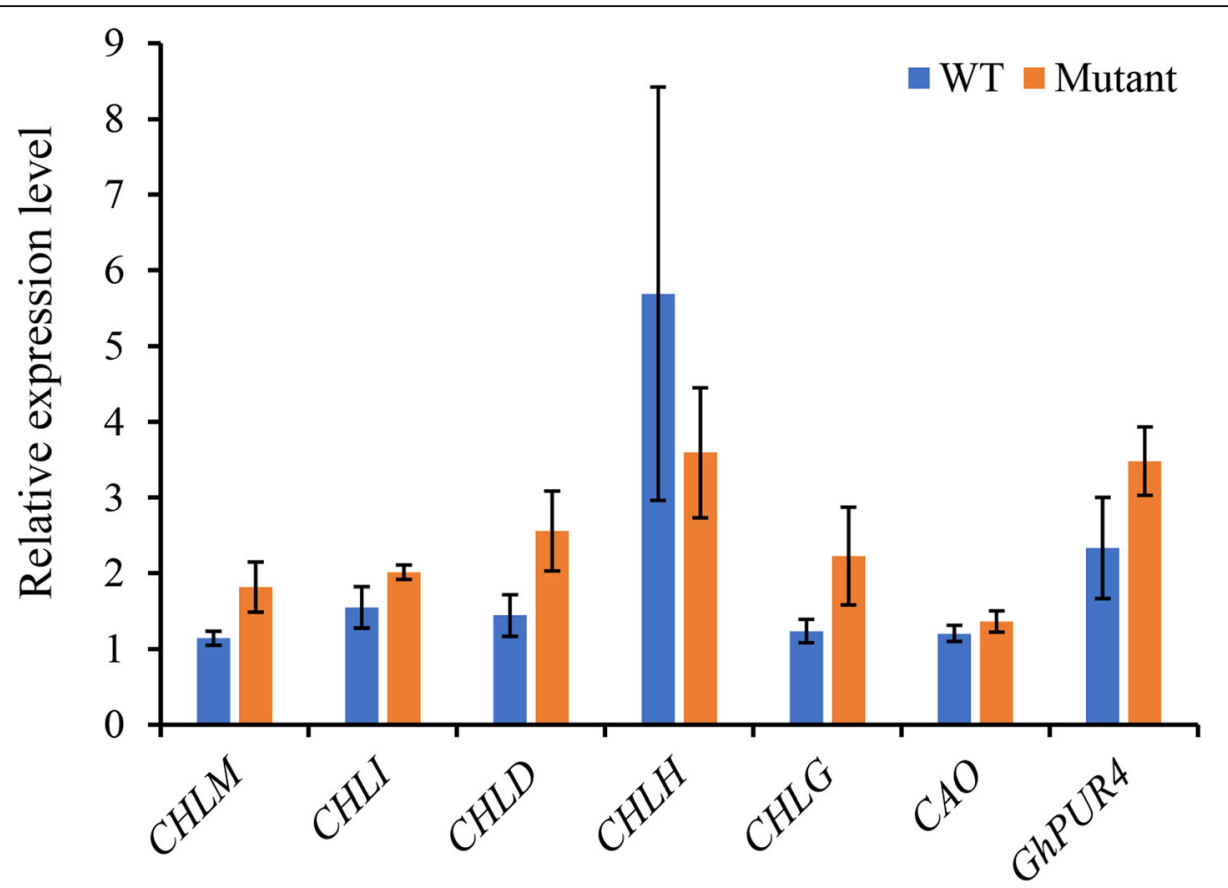

Fig. 3 Relative levels of genes in chlorophyll synthesis via qPCR experiments (mean \pm SD). *Significantly different between wild type (WT) and virescent mutant of Sumian 22 cotton $(P<0.05)$

Yellow leaf mutants are often associated with disruptions of photosynthetic pathway, including the regulatory network of chlorophyll biosynthesis and chloroplast development genes. Comparative genome sequencing of WT and mutant only identified one candidate mutation region, which contained 31 genes. In these genes, only ABCI1 was significantly downregulated in mutant in comparison to WT, and functionally related to chlorophyll synthesis. $\mathrm{ABC}$ transporter proteins belong to a large, diverse and ubiquitous superfamily [31]. Plants contain a collection of $\mathrm{ABC}$ proteins, which are similar to the components of prokaryotic multi-subunit $\mathrm{ABC}$ transporters, namely $\mathrm{ABC}$ group I. In Arabidopsis and rice, $\mathrm{ABCI}$ is required for proper formation of chloroplast structure, and biosynthesis of chlorophyll precursor. In addition, ABCI has been characterized as a FR light-specific signaling factor involved in the phytochrome A signaling pathway [30, 32]. During the chlorophyll biosynthesis, protoporphyrinogen IX is relocated from the stroma to the plastid envelope, where it is oxidized by the envelope-bound PPO to form protoporphyrin IX [33]. The generated proto IX then returns to the stroma by yet an unknown mechanism, participating in the synthesis of Mg-proto IX and downstream substances [34]. ABCI1 possibly transfers proto-IX formed on the plastid envelope into the stroma for chlorophyll biosynthesis [30]. Thus, deceased ABCI1 level would negatively affect the amount of proto IX in plastid and subsequently decrease the amounts of Mg-proto IX,
Pchld and finally chlorophylls in leaves. Experimental determination really showed significantly lower contents of Mg-proto IX and Pchld (Fig. 5), further supporting that $\mathrm{ABCI} 1$ might be a mechanism underlying virescent mutation in Sumian 22 (Fig. 6).

Based on the genome sequences, regulatory mechanisms of ABCI1 transcription were further explored. Nine SNPs were observed in $\mathrm{ABCI} 1$ sequence and its upstream $1000 \mathrm{bp}$ region. Among them, the mutations C3329472G and $\mathrm{T} 3330502 \mathrm{C}$ could be excluded from the potential regulatory mechanisms of $\mathrm{ABCI} 1$, because these two mutations were heterozygous in mutant (Additional file 1: Table S3), which was contradicted to the results of crossbreed experiments that the virescent mutation was recessive in Sumian 22. The mutations G3330282C, C3330324T, A3330374T, T3330536C, C3330589A, and C3330981T might also be excluded, because these mutations were located upstream to both Ghir_D10G003980 (ABCI1) and Ghir_D10G003990 (Additional file 1: Table S3). Thus, these mutations should regulate the transcription of both genes. However, qPCR revealed different changing tendencies between mutant and WT (Fig. 4). Finally, only the mutation A3330215T was left. This mutation was located at an AT-rich region of the 5'-UTR of $\mathrm{ABCI} 1$ and is $-317 \mathrm{bp}$ from the start codon of ABCI1. As reported, a long AT-rich region between positions from 350 to $-161 \mathrm{bp}$ relative to the transcription start site could function as a cryptic enhancer element regulating the transcription of the following gene in transgenic 


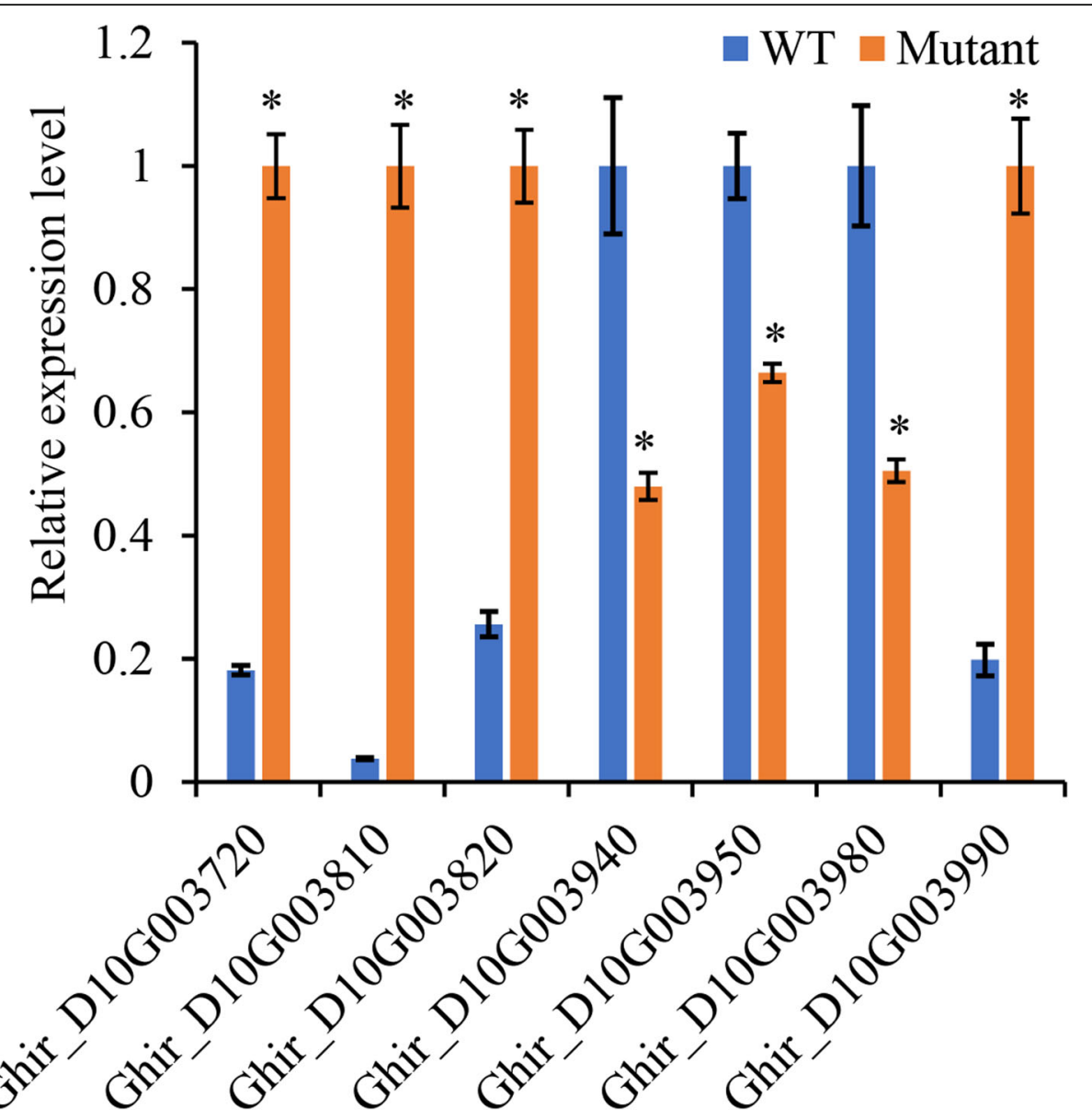

Fig. 4 Relative levels of genes in the candidate mutated region in virescent mutant (Mutant) compared with wild type (WT) of Sumian 22 cottons via qPCR experiments (mean \pm SD). *Significantly different between WT and Mutant $(P<0.01$ ). Ghir_D10G003720: Protein SRG1 (SRG1); Ghir_D10G003810: Floral homeotic protein AGAMOUS (AG); Ghir_D10G003820: Integrin-linked protein kinase 1 (ILK1); Ghir_D10G003940: ER lumen protein-retaining receptor A (ERD2A); Ghir_D10G003950: Protein gravitropic in the light 1 (GIL1); Ghir_D10G003980: ABC transporter I family member 1 (ABCI1); Ghir_D10G003990: unknown
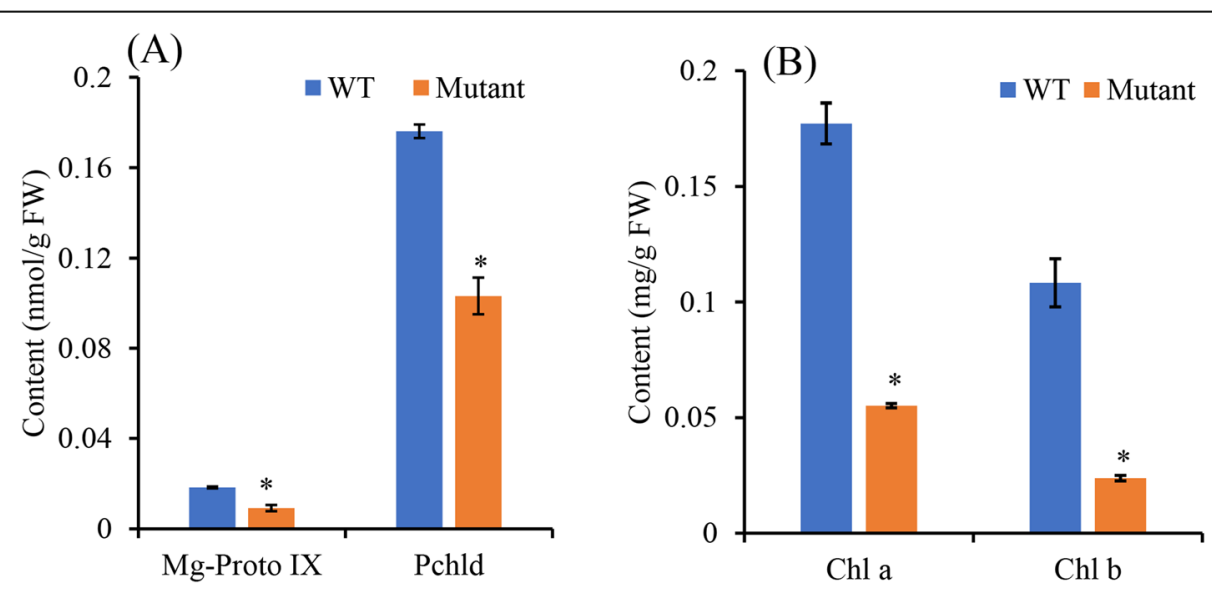

Fig. 5 Contents of chlorophyll precursors (A) and chlorophylls (B) in virescent mutant (Mutant) compared with wild type (WT) of Sumian 22 cottons (mean \pm SD). *Significantly different between WT and Mutant $(P<0.01)$ 


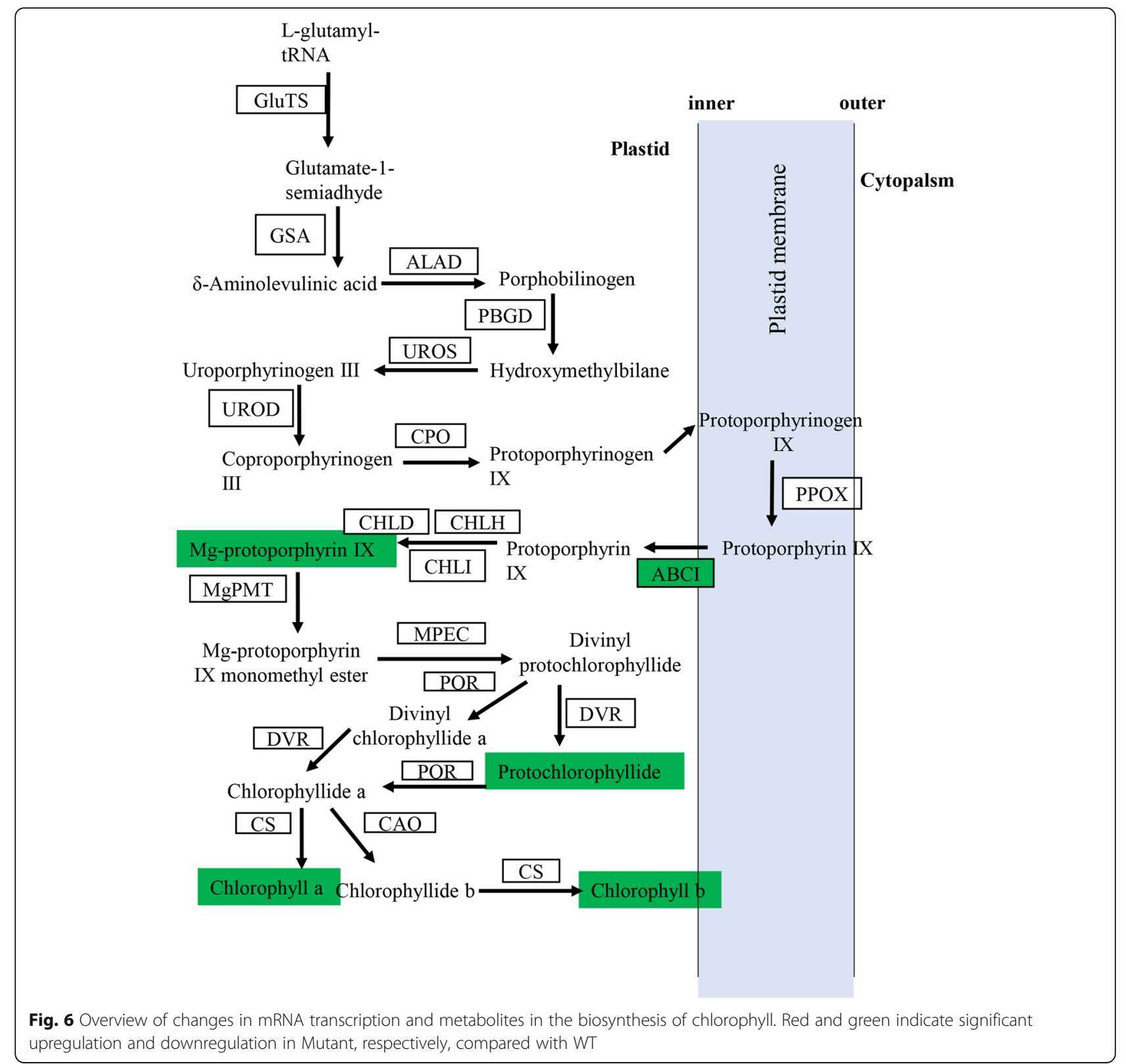

Arabidopsis plants [35]. More investigations are required to validate the regulatory functions of A3330215T mutation on $\mathrm{ABCI} 1$ transcription in cotton.

\section{Conclusions}

Virescent mutation in Sumian 22 cotton is recessive. Compared with WT, transcription of ABCI1 was lowered in mutant, inhibiting the transportation of protoporphyrin IX (proto IX) to plastid, and then suppressing the synthesis of Mg-protoporphyrin IX (Mg-proto IX), Protochlorophyllide (Pchld) and finally chlorophylls. These molecular changes are the mechanisms underlying the virescent trait in Sumian 22. The mutation from $\mathrm{A}$ to $\mathrm{T}$ at the -317 bp position might be the reason to mediate ABCI1 transcription in Sumian 22.

\section{Materials and methods}

\section{Plant materials and cross-breeding}

No special permissions and/or licenses were required for the present study. The collection of all plant materials complied with all current Chinese laws and regulations. The seeds of mutant and WT of Sumian 22 were provided by the Agricultural Sciences Research Institute of Coastal Region of Jiangsu Province (Yancheng, China). Mutant was crossed with WT, and the obtained $F_{1}$ plants were self-pollinated to produce an $\mathrm{F}_{2}$ population. Finally, $967 \mathrm{~F}_{2}$ seedlings were obtained. These operations 
were performed at the Nanyang Experimental Station of the Agricultural Sciences Research Institute of Coastal Region of Jiangsu Province (Yancheng, China). The numbers of green and yellow plants were counted to calculated the segregation ratio, and the data were analyzed using the $x^{2}$ test. In addition, fresh green and yellow leaves were collected and stored at $-80{ }^{\circ} \mathrm{C}$ for further molecular analyses.

\section{Whole genome re-sequencing, and BSA-seq analysis}

Leaves from WT, Mutant were extracted using a Biospin plant genomic DNA extraction kit (Bioer, Hangzhou, China). In addition, green leaves (G-pool) and yellow leaves (Y-pool) from the $F_{2}$ population were pooled separately and then subjected to DNA extraction. For each sample, leaves from at least 40 individuals were mixed. DNA degradation and contamination were monitored on $1 \%$ agarose gels. DNA purity was checked using a NanoPhotometer spectrophotometer (IMPLEN, CA, USA). DNA concentration was measured using a Qubit DNA assay kit on a Qubit 2.0 Fluorometer (Life Technologies, CA, USA). Sequencing libraries were prepared using a NEBNext Ultra DNA Library Prep Kit for Illumina following the manufacturer's instruction and subjected to the whole genome sequencing (WGS) using an Illumina HiSeq2500 platform. Paired-end reads were collected. After filtering low-quality reads, the obtained clean data of the two parents and two pools of F2 population were aligned to the reference genome of G. hirsutum (AD1) [35] using Burrows-Wheeler Aligner (BWA) (0.7.10-r789) with the default parameters [36]. Alignment/Map (SAM) tools were used to sort and index the resulted Binary Alignment Map (BAM) format files [37]. Mark duplicates in Picard tools (v1.102) (http:// broadinstitute.github.io/picard/) was used to discard duplicates, and the final sorted bam results were used for downstream analysis. For all samples, SNP calling was conducted using the Unified Genotype function of the Genome Analysis ToolKit (GATK) (v 3.6) software [38], and then variant calling was performed for SNP and small InDels between bulks.

To identify candidate genomic regions responsible for virescent gene, the SNP-index between the G-pool and Y-pool was estimated as a proportion of reads aligned to a position with a variant nucleotide different from the reference sequence. In order to improve the accuracy of the identified candidate regions, consecutive low depth SNPs were classified into a block with a minimum read depth of 20. A sliding window of $1 \mathrm{Mb}$ long and $10 \mathrm{~kb}$ step size was used to measure the average distribution of all SNP-indices. The $\triangle$ SNP-index was calculated by subtracting the SNP-index of the G-pool from the Y-pool. Genomic regions with $\triangle$ SNP-index higher than the threshold line were considered as candidate regions.
Sequences of genes in the candidate regions were extracted, blasted against $\mathrm{Nr}$, Swissport databases for annotation. Alignment of gene and protein sequences were performed using the ClustalX v2.1 software.

\section{RNA extraction and RT-qPCR}

Total RNA was extracted from young leaves of mutant and WT plants using a Plant RNA extraction kit (Bioer, Hangzhou, China). Their quality and quantity were examined using an Agilent Bioanalyzer 2100 (Agilent, USA) and a Qubit RNA assay kit on a Qubit 2.0 Fluorometer (Life Technologies, CA, USA). Then, total RNA were reversed to CDNA using a Prime Script II $1^{\text {st }}$ strand cDNA synthesis kit (Baosheng Bioengineering Institute, Dalian, China). RT-qPCR assays were conducted using SYBR Premix Ex Taq (Baosheng, Dalian, China) on a Gene9600 Plus RT-qPCR machine (Bioer, Hangzhou, China). In total, 31 genes in the candidate regions of the BSA results and seven genes related to chlorophyll biosynthesis were selected for RT-qPCR. The gene names and primers are listed in Additional file 1: Table S3. The cotton actin gene was used as the internal reference. Transcription levels of each gene were compared by calculating their relative change folds using the $2^{-\Delta \Delta \mathrm{Ct}}$ method [39]. For each stain, three biological replicates were included.

\section{Measurement of chlorophyll contents}

The contents of chlorophyll $\mathrm{a}$ and $\mathrm{b}$ (chl-a and chl-b) were measured for WT and mutant leaves [40]. Briefly, fresh leaf samples $(0.03 \mathrm{~g})$ were homogenized in $1 \mathrm{ml}$ of extraction solution (acetone:absolute ethanol $=1: 1$ ) and then extracted for $18 \mathrm{~h}$ in darkness. After centrifugation at $13,000 \mathrm{~g}$ for $5 \mathrm{~min}$, the absorbance values at 645 and $663 \mathrm{~nm}$ were measured using a UV4800 spectrophotometer (Unico, Shanghai, China), with the extraction buffer as the blank control. Each treatment was assayed with three biological replicates. Contents of chl-a and chl-b were calculated using the following equations.

$$
\begin{aligned}
& \mathrm{Chl}-\mathrm{a}=\left(12.7 \mathrm{~A}_{663}-2.69 \mathrm{~A}_{645}\right) \times \mathrm{V} /(1000 \times \mathrm{W}) \\
& \mathrm{Chl}-\mathrm{b}=\left(22.9 \mathrm{~A}_{645}-4.68 \mathrm{~A}_{663}\right) \times \mathrm{V} /(1000 \times \mathrm{W})
\end{aligned}
$$

where, $\mathrm{A}_{645}$ and $\mathrm{A}_{663}$ represent the absorbance at 645 and $663 \mathrm{~nm}$, respectively. W indicates the sample weight (g).

\section{Measurement of contents of chlorophyll synthesis precursors}

To validate the predicted changes of metabolites based on the qPCR results, contents of Mg-proto IX and Pchld were measured using the Hodgins's method [41]. Briefly, fresh leaf samples $(0.05 \mathrm{~g})$ were homogenized in $1 \mathrm{ml}$ of extraction solution (acetone:ammonia $=9: 1$ ), and then centrifuged at 13,000 $\mathrm{g}$ for $10 \mathrm{~min}$. The absorbances were 
measured at 575, 590 and $628 \mathrm{~nm}$. Next, the Mg-proto IX and Pchld contents were calculated using the following equations.

$$
\begin{aligned}
\text { Mg }- \text { protoIX }= & 0.06077 \times \mathrm{A}_{590}-0.01937 \\
& \times \mathrm{A}_{575}-0.003423 \times \mathrm{A}_{628} \\
\text { Pchld }= & 0.03563 \times \mathrm{A}_{628}+0.007225 \times \mathrm{A}_{590}-0.02955 \\
& \times \mathrm{A}_{575}
\end{aligned}
$$

where $A_{575}, A_{590}$ and $A_{628}$ indicate the absorbance at 575,590 and $628 \mathrm{~nm}$, respectively.

\section{Statistical analysis}

Difference in all indices between WT and Mutant were analyzed by the Student's $t$-test. Values were considered significantly different with the threshold of $P<0.05$.

\section{Abbreviations}

ABCl1: $A B C$ transporter I family member 1; BP: Biological processes; BSA: Bulked-segregant analysis; CC: Cellular components; CHLI: Mg-chelatase I subunit; SNP: Single nucleotide polymorphisms; Mutant: Virescent mutant; WT: Wild green type

\section{Supplementary Information}

The online version contains supplementary material available at https://doi. org/10.1186/s12864-021-07810-z.

Additional file 1. Additional results. Additional figures and tables in the docx format. Figure S1. Sequences of GhABCl1 in virescent mutant and wild type. The mutation at 3330215 from $T$ to $A$ is labeled in white back ground. Start and stop codons are labeled in black frame. Table S1. Summary of genome sequencing data. Table S2. The SNPs potentially affecting Ghir-D10G003980 transcription. Table S3. Oligonucleotide primers used in the present study.

\section{Authors' contributions}

JG, YS and LWC designed experiment and did the analysis. WW, YHW and HY conducted the experiment. QHS and JPC wrote the paper. YRS supervised the experiment and revised the manuscript. All authors read and approved the final manuscript

\section{Funding}

This work was supported by the Natural Science Foundation of Jiangsu Province (BK20181210), the National Key Research and Development Program of China (2016YFD0101421), State Key Laboratory of Crop Genetics and Germplasm Enhancement Open Fund (ZW202007), and Jiangsu Collaborative Innovation Center for Modern Crop Production project (No.10).

\section{Availability of data and materials}

The raw data of whole sequencing have been deposited in the NCB database with the access number of PRJNA733888 (https://www.ncbi.nlm. nih.gov/bioproject/PRJNA733888).

\section{Declarations}

\section{Ethics approval and consent to participate}

No special permissions and/or licenses were required for the present study. The collection of all plant materials complied with all current Chinese laws and regulations.

\section{Consent for publication}

Not applicable.

\section{Competing interests}

The authors declare no conflicts of interest.

Received: 9 March 2021 Accepted: 14 June 2021

Published online: 03 July 2021

\section{References}

1. Mao G, Ma Q, Wei H, Su J, Wang H, Ma Q, Fan S, Song M, Zhang X, Yu $S$. Fine mapping and candidate gene analysis of the virescent gene $V$ (1) in Upland cotton (Gossypium hirsutum). Mol Genet Genomics. 2018; 293(1):249-64.

2. Zhao Y, Wang M, Zhang YZ, Du LF, Pan T. A chlorophyll-reduced seedling mutant in oilseed rape, Brassica napus, for utilization in F1 hybrid production. Plant Breed. 2000;119:131-5.

3. Lopez-Juez E, Jarvis P, Takeuchi A, Page A, Chory J. New Arabidopsis cue mutants suggest a close connection between plastid- and phytochrome regulation of nuclear gene expression. Plant Physiol. 1998;118:803-15.

4. Iba K, Takamiya Kl, Toh Y, Satoh H, Nishimura M. Formation of functionally active chloroplasts is determined at a limited stage of leaf development in virescent mutants of rice. Dev Genet. 1991;12(5):342-8.

5. Aalders LE. "Yellow cotyledon", a new cucumber mutation. Can J Genet Cytol. 1959;1(10):10-2

6. Hopkins W, Elfman B. Temperature-induced chloroplast ribosome deficiency in virescent maize. J Hered. 1984;75(3):207-11.

7. Killough D, Horlacher W. The inheritance of virescent yellow and red plant colors in cotton. Genetics. 1933:18:329-34.

8. Beale SI. Green genes gleaned. Trends Plant Sci. 2005;10(7):309-12.

9. Nagata N, Tanaka R, Satoh S, Tanaka A. Identification of a vinyl reductase gene for chlorophyll synthesis in Arabiopsis thalinana. Plant Cell Physiol. 2005:17:233-40.

10. Wu Z, Zhang X, He B, Diao L, Sheng S, Wang J, Guo X, Su N, Wang LF, Jiang $L$, et al. A chlorophyll-deficient rice mutant with impaired chlorophyllide esterification in chlorophyll biosynthesis. Plant Physiol. 2007;145:29-40.

11. Zhu J, Chen J, Gao F, Xu C, Wu H, Chen K, Si Z, Yan H, Zhang T. Rapid mapping and cloning of the virescent- 1 gene in cotton by bulked segregant analysis-next generation sequencing and virus-induced gene silencing strategies. J Exp Bot. 2017:68:4125-35.

12. Zhang Y, Wang Q, Zuo D, Cheng H, Liu K, Ashraf J, Li S, Feng X, Yu J, Song $\mathrm{G}$. Map-based cloning of a recessive gene $\mathrm{v} 1$ for virescent leaf expression in cotton (Gossypium spp.). J Cotton Res. 2018;1:10.

13. Zhang T, Hu Y, Jiang W, Fang L, Guan X, Chen J, Zhang J, Saski C, Stelly D, Hulse-Kemp A et al. Sequencing of allotetraploid cotton (Gossypium hirsutum L. acc. TM-1) provides a resource for fiber improvement. Nat Biotechnol. 2015:33(5):531-7.

14. Mao G, Wei H, Hu W, Ma Q, Zhang M, Wang H, Yu S. Fine mapping and molecular characterization of the virescent gene vsp in Upland cotton (Gossypium hirsutum). Theor Appl Genet. 2019;132(7):2069-86.

15. Wang W, Pan Z, Pan Q. Industrialization of cotton cultivar "Sumian 22" and correlative breeding problems. Acta Agric Jiangxi. 2009;21(4):24-7 (In Chinese).

16. Cai L, Pan Q, Shi Q, Wang W, Pan Z, Chen J. Breeding and cultivation techniques of Sumian 22. Jiangxi Cotton. 2010;32(5):47-8 (In Chinese).

17. He Z, Yin M, Xie Z, Wang Y, Shen J, Li L. Genetic analysis and breeding application of a novel rice mutant with virescent yellow leaves. Chin J Trop Crops. 2013:34(11):2145-9 (In Chinese).

18. Giovannoni JJ, Wing RA, Ganal MW, Tanksley SD. Isolation of molecular markers from specific chromosomal intervals using DNA pools from existing mapping populations. Nucleic Acids Res. 1991;19(23):6553-68.

19. Michelmore R, Paran I, Kesseli R. Identification of markers linked to diseaseresistance genes by bulked segregant analysis: a rapid method to detect markers in specific genomic regions by using segregating populations. Proc Natl Acad Sci USA. 1991;88:9828-32.

20. Abe A, Kosugi S, Yoshida K, Natsume S, Takagi H, Kanzaki H, Matsumura H, Yoshida K, Mitsuoka C, Oli MT, et al. Genome sequencing reveals agronomically important loci in rice using MutMap. Nat Biotechnol. 2012;30: $174-8$.

21. Liu H, Zhou F, Zhou T, Yang $Y$, Zhao $Y$. Fine mapping of a novel male-sterile mutant showing wrinkled-leaf in sesame by BSA-Seq technology. Ind Crop Prod. 2020;156:112862

22. Zhao C, Liu L, Safdar L, Meili X, Cheng X, Liu Y, Xiang Y, Tong C, Tu J, Huang $J$, et al. Characterization and fine mapping of a yellow-virescent gene 
regulating chlorophyll biosynthesis and early stage chloroplast development in Brassica napus. G3 (Bethesda) 2020;10(9):3201-11.

23. Hongwei Z, Wang X, Qingchun P, Li P, Liu Y, Lu X, Zhong W, Li M, Han L, Li J, et al. QTG-seq accelerates QTL fine mapping through QTL partitioning and whole-genome sequencing of bulked segregant samples. Mol Plant. 2019;12(3):426-37.

24. Mascher M, Jost M, Kuon J-E, Himmelbach A, Aßfalg A, Beier S, Scholz U, Graner A, Stein N. Mapping-by-sequencing accelerates forward genetics in barley. Genome Biol. 2014;15:R78.

25. Cui B, Pan Q, Clarke D, Ochoa-Villarreal M, Umbreen S, Yuan B, Shan W, Jiang J, Loake G. S-nitrosylation of the zinc finger protein SRG1 regulates plant immunity. Nat Commun. 2018;9:1-12.

26. von Numers N, Survila M, Aalto M, Batoux M, Heino P, Palva ET, Li J. Requirement of a homolog of glucosidase II beta-subunit for EFR-mediated defense signaling in Arabidopsis thaliana. Mol Plant. 2010;3(4):740-50.

27. Ray A, Robinson-Beers K, Ray S, Baker S, Lang J, Preuss D, Milligan S, Gasser C. Arabidopsis floral homeotic gene BELL (BELI) controls ovule development through negative regulation of AGAMOUS gene (AG). Proc Natl Acad Sci USA. 1994;91:5761-5.

28. Allen T, Ingles P, Praekelt U, Smith H, Whitelam G. Phytochrome-mediated agravitropism in Arabidopsis hypocotyls requires GIL1 and confers a fitness advantage. Plant J. 2006;46:641-8.

29. Tommasini R, Vogt E, Fromenteau M, Hörtensteiner S, Matile P, Amrhein N, Martinoia E. An ABC-transporter of Arabidopsis thaliana has both glutathione-conjugate and chlorophyll catabolite transport activity. Plant J. 1998;13:773-80

30. Moller S, Kunkel T, Chua NH. A plastidic ABC protein involved in intercompartmental communication of light signaling. Genes Dev. 2001;15: 90-103.

31. Rea PA. Plant ATP-binding cassette transporters. Annu Rev Plant Biol. 2007: 58:347-75.

32. Zeng X, Tang R, Guo H, Ke S, Teng B, Hung YH, Xu Z, Xie XM, Hsieh TF, Zhang XQ. A naturally occurring conditional albino mutant in rice caused by defects in the plastid-localized OsABCI8 transporter. Plant Mol Biol. 2017; 94:137-48.

33. Reinbothe S, Reinbothe C. Regulation of chlorophyll biosynthesis in angiosperms. Plant Physiol. 1996;111(1):1-7.

34. Wu K, Hu M, Martin T, Wang C, Li XQ, Tian L, Brown D, Miki B. The cryptic enhancer elements of the tCUP promoter. Plant Mol Biol. 2003;51(3):351-62.

35. Wang M, Tu L, Yuan D, Zhu D, Chao S, Li J, Liu F, Pei L, Wang P, Zhao G, et al. Reference genome sequences of two cultivated allotetraploid cottons, Gossypium hirsutum and Gossypium barbadense. Nat Genet. 2019;51:224-9.

36. Li H, Durbin R. Fast and accurate short read alignment with BurrowsWheeler transform. Bioinformatics. 2009;25(14):1754-60.

37. Li H, Handsaker B, Wysoker A, Fennell T, Ruan J, Homer N, Marth G, Abecasis G, Durbin R, Subgroup GPDP. The sequence alignment/map format and SAMtools. Bioinformatics. 2009;25(16):2078-9.

38. McKenna A, Hanna M, Banks E, Sivachenko A, Cibulskis K, Kernytsky A, Garimella K, Altshuler D, Gabriel S, Daly M, et al. The Genome Analysis Toolkit: a MapReduce framework for analyzing next-generation DNA sequencing data. Genome Res. 2010;20(9):1297-303.

39. Livak K, Schmittgen T. Analysis of relative gene expression data using realtime quantitative PCR. Methods. 2002;25:402-8.

40. Li D, Yun H, Guo H, Mu F, Gong X, Zhang M. Mixture solution soaking extraction efficiencies of chlorophyll from maize. J Maize Sci. 2006;14(1): 117-9 (In Chinese).

41. Hodgins RR, van Huystee R. Rapid simultaneous estimation of protoporphyrin and Mg-porphyrins in higher plants. J Plant Physiol. 1986; 125:311-23.

\section{Publisher's Note}

Springer Nature remains neutral with regard to jurisdictional claims in published maps and institutional affiliations.

Ready to submit your research? Choose BMC and benefit from:

- fast, convenient online submission

- thorough peer review by experienced researchers in your field

- rapid publication on acceptance

- support for research data, including large and complex data types

- gold Open Access which fosters wider collaboration and increased citations

- maximum visibility for your research: over $100 \mathrm{M}$ website views per year

At BMC, research is always in progress.

Learn more biomedcentral.com/submissions 